\title{
DÜBLIN
}

Technological University Dublin

ARROW@TU Dublin

\section{Localised Laser Joining of Glass to Silicon with BCB Intermediate Layer}

\author{
Qiang wu \\ Technological University Dublin, qiang.wu@tudublin.ie \\ N. Lorenz \\ Heriot Watt University \\ Duncan Hand \\ Heriot-Watt University
}

Follow this and additional works at: https://arrow.tudublin.ie/engscheceart

\section{Recommended Citation}

Qiang Wu, N. Lorenz, and D.P. Hand, "Localised laser joining of glass to silicon with BCB intermediate layer", Microsystem Technologies, vol. 15, no. 7, pp. 1051-1057, 2009. doi:10.1007/s00542-009-0879-1

This Article is brought to you for free and open access by the School of Electrical and Electronic Engineering at ARROW@TU Dublin. It has been accepted for inclusion in Articles by an authorized administrator of ARROW@TU Dublin. For more information, please contact arrow.admin@tudublin.ie, aisling.coyne@tudublin.ie, gerard.connolly@tudublin.ie.

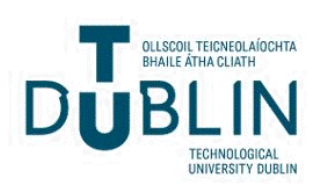




\title{
Localised laser joining of glass to silicon with BCB intermediate layer
}

\author{
Qiang $\mathrm{Wu}^{1,2}$, N. Lorenz ${ }^{1}$ and D.P. Hand ${ }^{1}$ \\ 1. Applied Optics and Photonics Group, School of Engineering and Physical Sciences, Heriot-Watt University, UK, \\ Qiang Wu, email: Qiang.wu@dit.ie, telephone: +353-1-4024569; N. Lorenz, email: nl62@hw.ac.uk; D. P. Hand, \\ email: D.P.Hand@hw.ac.uk, telephone: +44-1314513020 \\ 2. Photonics Research Centre, School of Electronic and Communications Engineering, Dublin Institute of \\ Technology, Kevin Street, Dublin 8, Ireland
}

\begin{abstract}
The use of a laser to provide localised heating is an ideal solution to the problem of packaging micro-electro-mechanical-systems (MEMS) whilst maintaining a low device temperature to avoid changes in temperature-sensitive materials in the device. In this paper we present localised laser bonding of glass to silicon (normally used as the MEMS substrate) by using a fibre-delivered high power laser diode array to cure an intermediate layer of the thermosetting polymer Benzocyclobutene (BCB). In our experiments, we use two techniques to realise localised heating: one is to use an axicon together with a conventional positive lens to generate a ring focus; the other is to use a scanning focused laser beam. In both cases localised cooling is required to confine the elevated temperatures to the bonding area. Finite Element (FE) simulation indicates that both techniques should keep the temperature in the centre of the package to approximately that of the ambient environment ( $300 \mathrm{~K})$ during the process. However experiments show that the temperature in the centre of the package rises to a value of around 500K, likely due to poor contact between silicon and cooling sink. Experimentally, we confirmed that either technique can be used to obtain excellent bonding of glass to silicon with leak rate at a level of $10^{-10} \mathrm{mbar} \mathrm{l} \mathrm{s}^{-1}$, whilst keeping the centre of device at a lower temperature.
\end{abstract}

Keywords: Laser joining, BCB, Localised heating

\section{Introduction}

The majority of joining techniques (e.g. soldering, welding, brazing) require heating of the material in the vicinity of the joint, and it is of course the ability of the laser to provide the required heating in a highly localised and controlled manner that has led to its widespread application in many industrial sectors. In this paper we focus on a laser-based joining technique for micro-electro-mechanical-systems (MEMS). A number of different joining techniques have been developed for the packaging of MEMS devices, where highly sensitive micro-machined silicon-based devices require mechanical protection and the prevention of moisture and dust ingress, often whilst maintaining optical access via a glass window. Techniques currently used include anodic bonding [1-2] and fusion bonding [3-4], which locally require either strong electric fields (400-850 Volts) or high temperatures (>1300 K), where processes normally involve heating of the complete package to a high temperature. More recently, intermediate layer bonding has been carried out, using thermosetting polymers such as Benzocyclobutene (BCB), which has the advantage of a significantly reduced process temperature, whilst maintaining low moisture content and minimal outgassing. In applications where temperature-sensitive materials are required (e.g. in some RF-MEMS applications where material parameters are irreversibly modified by heating) it is desirable to reduce the process temperature still further (in previously reported work with BCB the complete package is heated on a hot plate or in an oven to effect curing [5-6]). In order to effect a sufficient degree of cure of BCB ( 90\%) using a hotplate, a temperature of $575 \mathrm{~K}$ is required for $10 \mathrm{~s}$ or $560 \mathrm{~K}$ for $20 \mathrm{~s}$ (Figure 1) [7].

Our previous work has shown that it is feasible to use a laser as a remote heat source to cure a BCB bonding layer between glass and silicon surfaces, hence joining them together [8]. The laser light passes through the glass slide, but is strongly absorbed close to the surface of the silicon, provided that its wavelength is $<1 \mu \mathrm{m}$. We were able to achieve excellent bonding with a uniform illumination from the laser, as described in [8]; however the entire device still heated up due to lateral heat flow. Therefore such a technique is clearly not suitable when we want to avoid heating of a temperature-sensitive MEMS device located in the centre of a 'ring' of BCB. Furthermore it was a highly energy inefficient process as more than $80 \%$ of the laser power was reflected by the mask which was used to protect 
the inside of the MEMS device from direct exposure. The mask also limited the flexibility of this process as for every different shape of bonding layer a new mask had to be produced.

The use of a localised heating technique can reduce significantly the temperature reached by the actual device being enclosed. This can be achieved either by using an embedded electrical heater incorporated during the MEMS manufacture process [9-12], requiring a more complex lithographic process; microwave heating [13]; or induction heating $[1,14]$. An alternative solution is to use localised laser heating. In this paper, we demonstrate two techniques to realise laser-based localised heating: (1) by using an axicon together with a conventional lens to generate a ring focus, designed to match the dimensions of a BCB ring deposited on the glass lid of the MEMS device; and (2) using a scanning focused laser beam which has virtually no limitations as regards the shape of the bonding layer.

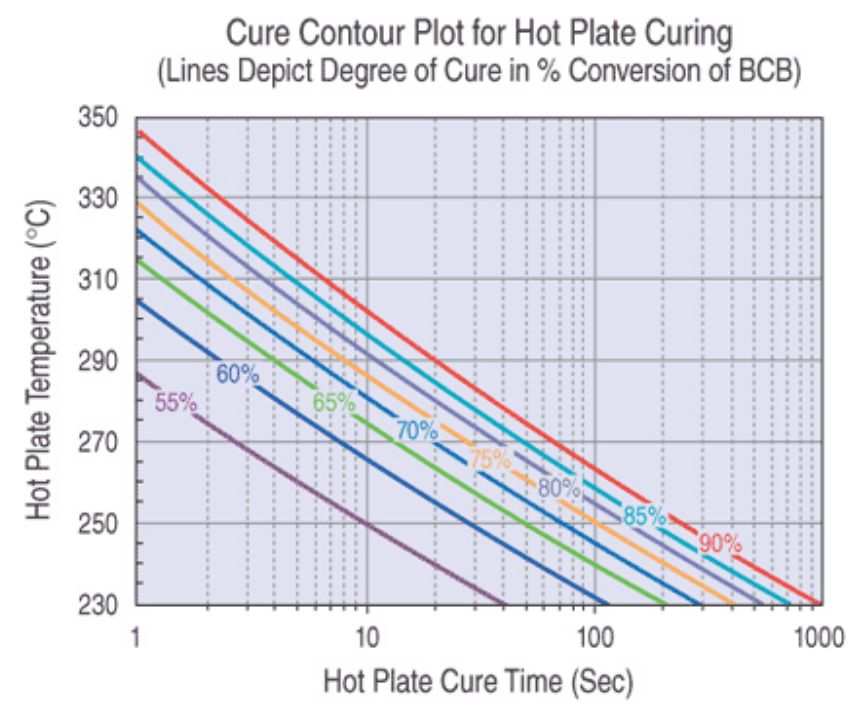

Figure 1: Degree of cure as a function of temperature and time [7]

\section{Localised heating with a focused ring}

An axicon is a cone-shaped optic, and in combination with a positive lens can create a 'ring focus'. Figure 2 shows a cross-section through an axicon-lens arrangement, demonstrating this effect, given the circular symmetry of the axicon:

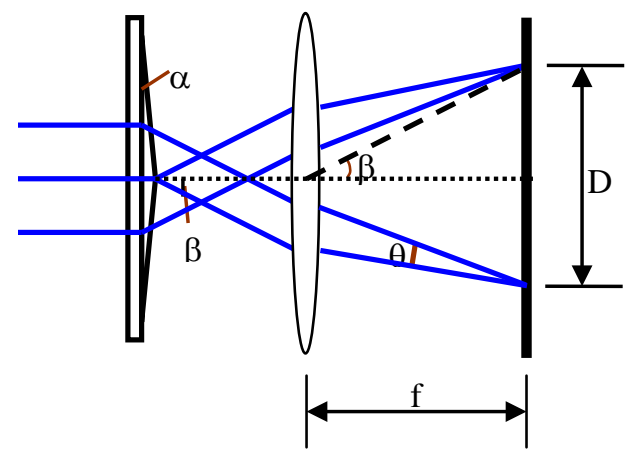

Figure 2: Schematic figure of an axicon ring. In our case $\alpha^{\prime}=10^{\circ}$ and $\mathrm{f}=38 \mathrm{~mm}$

In our setup, light from a 210W CW laser diode array is delivered through a $0.22 \mathrm{NA}, 200 \mu \mathrm{m}$ core diameter optical fibre. At the output of the fibre, the light is collimated with a $+100 \mathrm{~mm}$ focal length lens before passing through firstly the axicon followed by a $+38 \mathrm{~mm}$ focal length focusing lens (figure 3(a)) generating the beam profile shown in figure 3 (b). The diameter of the ring is $6.5 \mathrm{~mm}$ and its width is $0.3 \mathrm{~mm}$. 


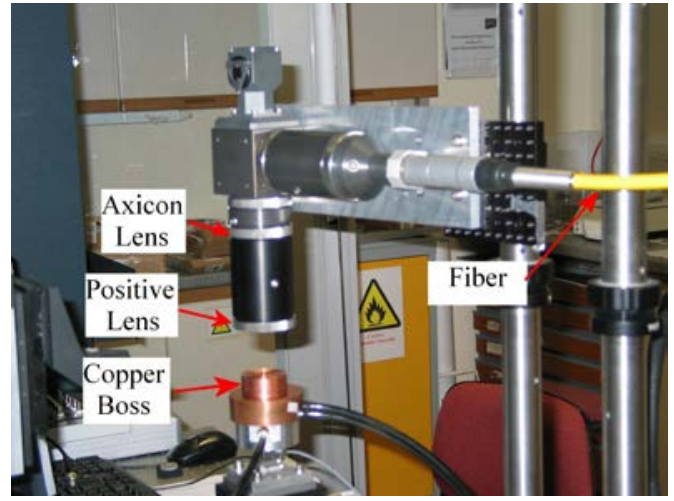

(a)

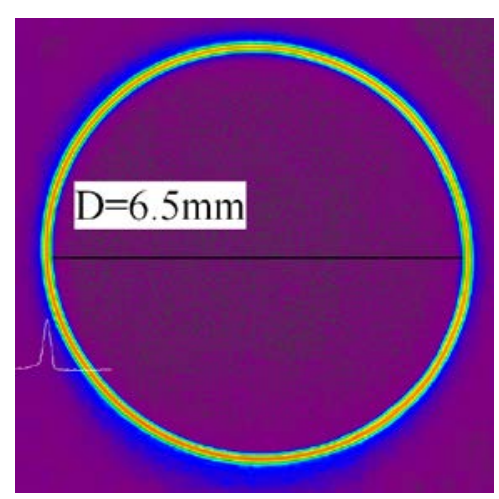

(b)

Figure 3: (a) Axicon lens laser system and (b) beam profile of this system

To prevent lateral heating of the centre of the substrate, it is necessary to place a cooled thermally conductive block (in our case copper was used) in contact with the underside of the silicon substrate, to act as a heat sink.

A schematic of the laser bonding arrangement is shown in Figure 4. The glass wafer was first spin-coated with BCB, which was then patterned using standard lithographic processes. The glass wafer was subsequently diced into chips. The silicon chip (the device substrate) was supported directly by a cooled copper block to prevent lateral heat transfer within the silicon, and a temperature indicating paint (Tempilaq, Tempil Inc) used to provide an indication of the maximum temperature reached in the centre of the silicon sample.

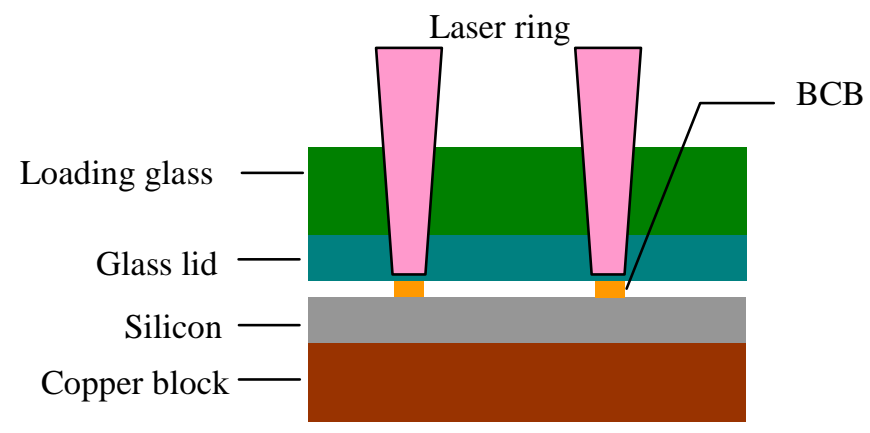

Figure 4: Schematic of cross sectional view of localised laser bonding using a laser ring with a BCB joining layer

In the special case of heat propagation in an isotropic and homogeneous medium in the 3-dimensional space, the heat equation is

$$
\frac{\partial u}{\partial t}=k\left(\frac{\partial^{2} u}{\partial^{2} x}+\frac{\partial^{2} u}{\partial^{2} y}+\frac{\partial^{2} u}{\partial^{2} z}\right)
$$

where:

$u=u(t, x, y, z)$ is temperature as a function of time and space; $k$ is a material-specific quantity depending on the thermal conductivity, the density and the heat capacity. Specifically, $k=\kappa / \mathrm{c} \rho$ where $\kappa$ is the thermal conductivity, $\mathrm{c}$ is the specific heat, and $\rho$ the density.

By using the heat equation above, we carried out a three dimensional simulation of the laser-based process with software FlexPDE. In our simulation, the laser power intensity is defined as Gaussian distribution

$$
I(r)=\frac{2 P}{\pi \omega^{2}}(1-R) \exp \left(-\frac{2 r^{2}}{\omega^{2}}\right)(2)
$$

Where $P$ is the laser output power, $R$ is the reflectivity of material, $\omega$ is the radius of the laser beam. 
In our model the materials and geometries are the same as those used experimentally (Figure 4), with the laser power assumed to be absorbed by the surface of silicon (reflectivity 31\%). The temperature at the bottom surface of the copper is set as $300 \mathrm{~K}$ because this is water cooled. To simplify the simulation process, we also assume the temperature at the top layer of glass is $300 \mathrm{~K}$ and there is no heat loss at other surfaces of the model.

Our simulation indicates that using a laser ring to cure a circular 'ring' of BCB, of diameter $6.5 \mathrm{~mm}$ and width $0.30 \mathrm{~mm}$, it is possible to keep the MEMS device area on the silicon essentially at room temperature, provided that the silicon is in good thermal contact with the cooled copper block. Figure 5 shows the calculated temperature field on the top surface of the silicon after 2 seconds of $200 \mathrm{~W}$ laser illumination. The width of the focused ring is assumed to be $0.3 \mathrm{~mm}$.

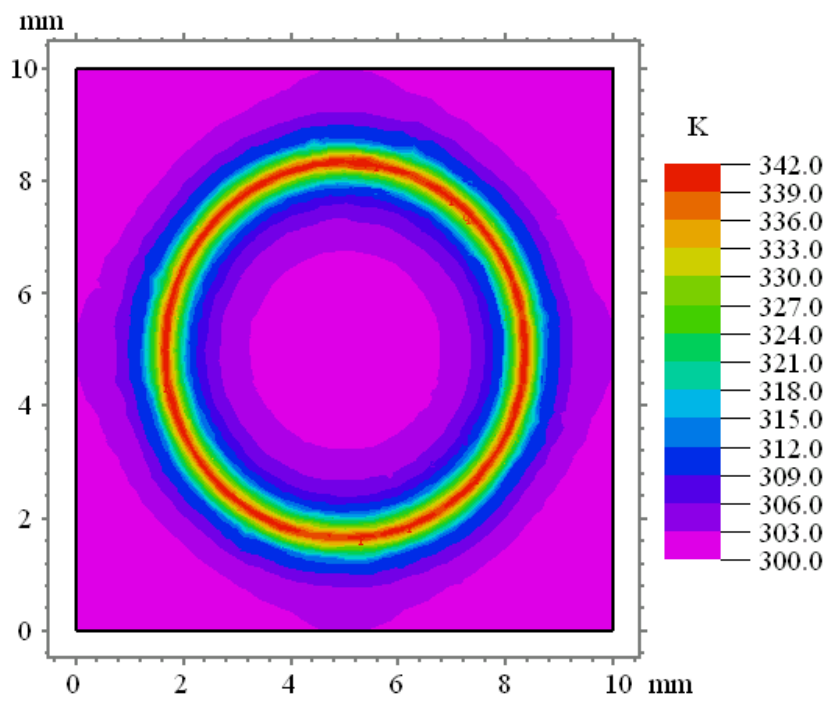

Figure 5: Calculated temperature field on silicon chip surface under laser ring illumination, with the silicon chip placed on a copper block after 2 seconds illumination

As expected, there is a significantly higher temperature along the focused laser beam ring than other parts of the sample. However, this temperature ( $342 \mathrm{~K}$ ) is too low for curing of the BCB ring; indeed the simulation reveals that a laser power of $1000 \mathrm{~W}$ is necessary to generate the required $580 \mathrm{~K}$ in the vicinity of the BCB ring whilst keeping the temperature at the centre of the device at room temperature. Another (less expensive) way to ensure that the device area remains cool whilst the BCB is cured is to provide heat sinking only at the centre of the silicon substrate - e.g. by using a "copper boss" heat sink to substitute for the copper block (Figure 6).

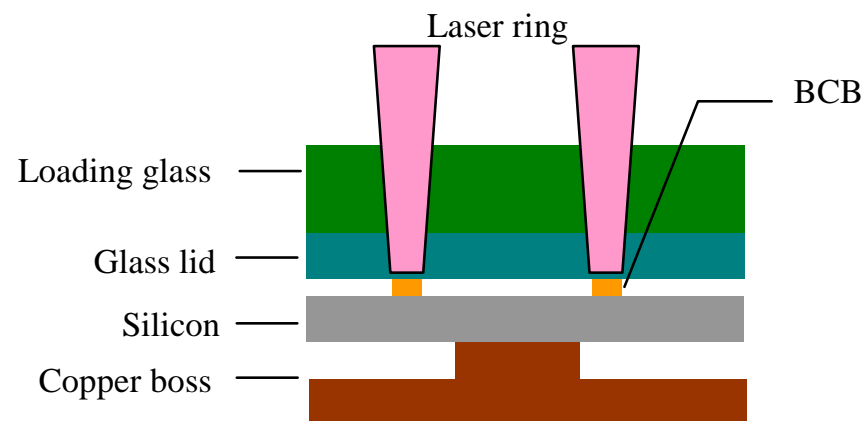

Figure 6: Schematic of localised laser bonding using a copper boss heat sink

The reduced overall heat loss results in a higher temperature in the BCB ring whilst maintaining a low temperature in the centre of the silicon, as confirmed in the FE simulation in Figure 7. In this simulation, the diameter of the copper boss is $4 \mathrm{~mm}$, the laser power is $170 \mathrm{~W}$ and laser illumination time is 2 seconds. It is clear from Figure 7 that the temperature in the vicinity of the BCB ring was around $610 \mathrm{~K}$ which is high enough to cure BCB ( the BCB is $90 \%$ cured after $1.5 \mathrm{~s}$ exposure to this temperature), whilst the centre of the device remains at around room temperature. 


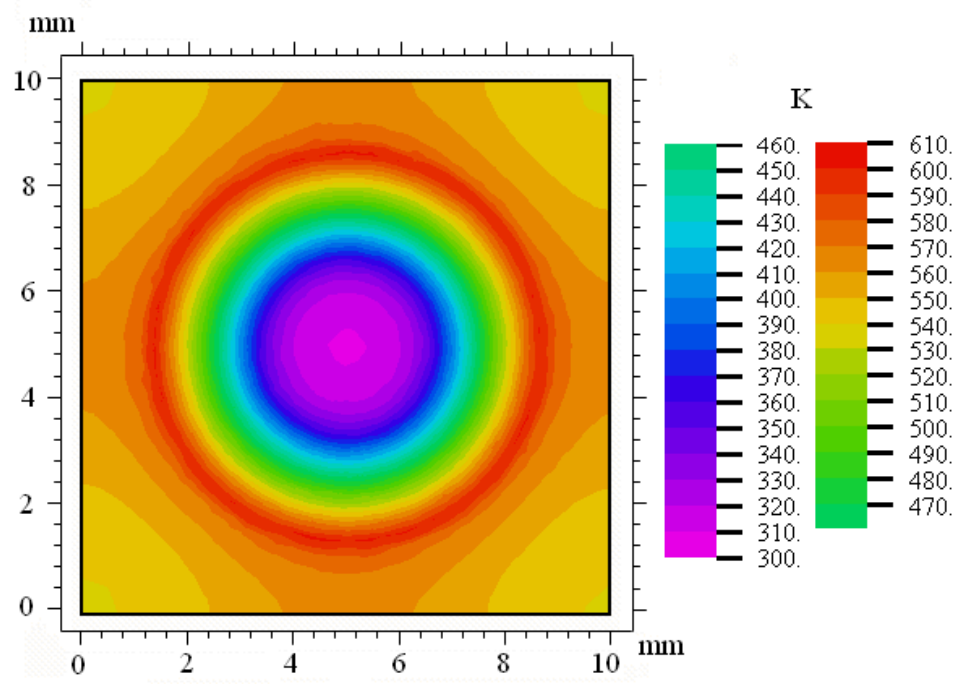

Figure 7: Calculated temperature field on silicon chip surface under laser ring illumination, with the silicon chip placed on a copper boss with good contact after 2 seconds illumination

Experiments based on copper block cooling were carried out. The thickness of BCB used in our experiments is 15 microns. As expected, it was not successful because of the temperature not being high enough to cure BCB. The copper block was then exchanged for the copper boss, resulting in successful joining with a force of $3.92 \mathrm{~N}$. The laser used was a fibre-delivered diode array operating at $940 \mathrm{~nm}$ (Laserline, $210 \mathrm{~W}$, fibre core diameter $200 \mu \mathrm{m}, \mathrm{NA}=0.22$ ). Successful bonding with a fully cured BCB layer could be achieved which was demonstrated by the neutral colour of the bonding BCB area when inspected under a microscope. The clear green colour of the uncured BCB film vanishes when it becomes fully cured.

To evaluate the quality of the bond hermeticity testing was undertaken. The standard test method - MIL-STD-883G cannot really be applied as it is not designed for such small cavity volumes $\left(<1 \mathrm{~mm}^{3}\right)$. Therefore additional samples were manufactured including a laser-drilled hole in the Si wafer, in order to test for hermeticity using a through-hole testing method [8] as shown in figure 8; a technique specially developed for low volume packages.

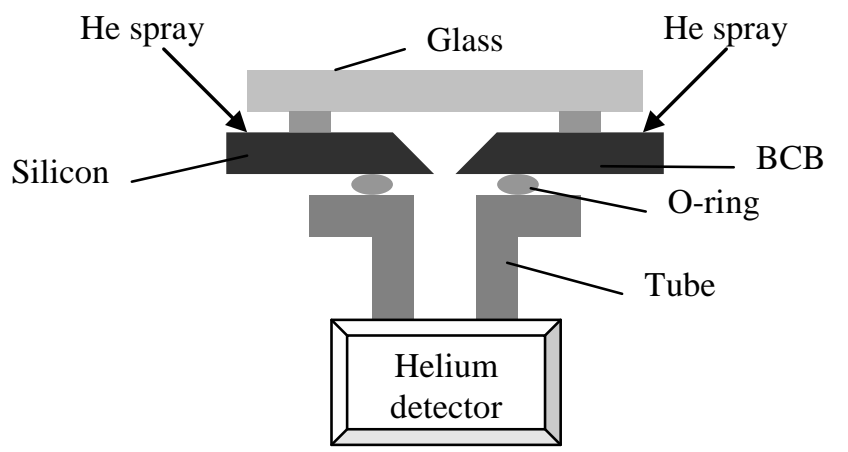

Figure 8: Sketch of through-hole Helium leak testing method

This method involves placing the sample directly onto a Helium leak detector, with an o-ring to prevent lateral ingress of Helium; spraying the Helium around the sample; and using a mass spectrometer to compare the signal with the background signal level. In our testing process, the background signal is obtained by replacing the sample with a planar silicon substrate without any hole and spraying with Helium. A typical value is around $2.5 \times 10^{-10} \mathrm{mbar} \mathrm{l} \mathrm{s}^{-1}$. Results for our laser-bonded samples are shown in table 1 below: 
Table 1 Fine leak test results of the bonded samples with axicon lens system

\begin{tabular}{|c|c|c|}
\hline $\begin{array}{c}\text { Laser Power } \\
(\mathrm{W})\end{array}$ & $\begin{array}{c}\text { Bonding } \\
\text { time (s) }\end{array}$ & $\begin{array}{c}\text { Leak rate } \\
\left(\mathrm{mbar} \mathrm{l} \mathrm{s}^{-1}\right)\end{array}$ \\
\hline 90 & 10 & $3.5 \times 10^{-10}$ \\
\hline 200 & 2 & $3.5 \times 10^{-10}$ \\
\hline 210 & 1 & $3.0 \times 10^{-10}$ \\
\hline
\end{tabular}

Table 1 indicates that the leak rate is not significantly affected by the laser power used, and it is close to the limit of the leak test machine.

In order to check the bonding behaviour of glass to silicon with BCB intermediate layer, a cross section of bonded sample is provide under a microscope as shown in figure 9.

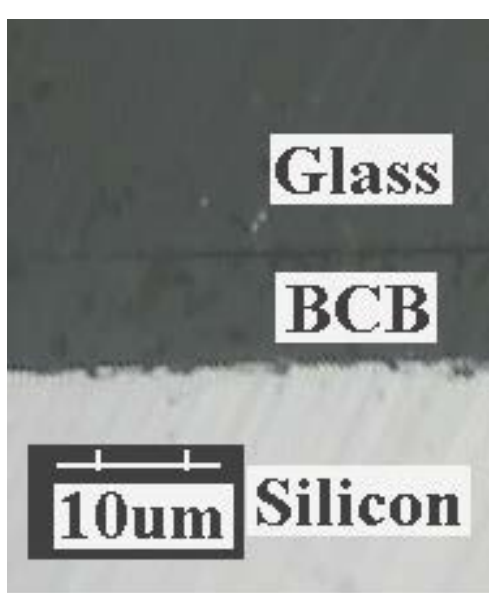

Figure 9: A cross section of bonded sample under a microscope

Figure 9 shows that BCB has good contact with both glass and silicon.

However, the Tempilaq paint demonstrates that the temperature in the centre of the silicon was between $505 \mathrm{~K}$ and $526 \mathrm{~K}$, rather than the $300 \mathrm{~K}$ predicted by the FE simulation. This must arise from poor thermal contact between the silicon and the copper. Further simulations as depicted in figure 10 show that even if there is just a $3 \mu \mathrm{m}$ thick air gap between the bottom of the silicon and the copper boss cooling element, the temperature in the centre of the silicon would reach $460 \mathrm{~K}$ when the temperature in the BCB ring was $630 \mathrm{~K}$. 


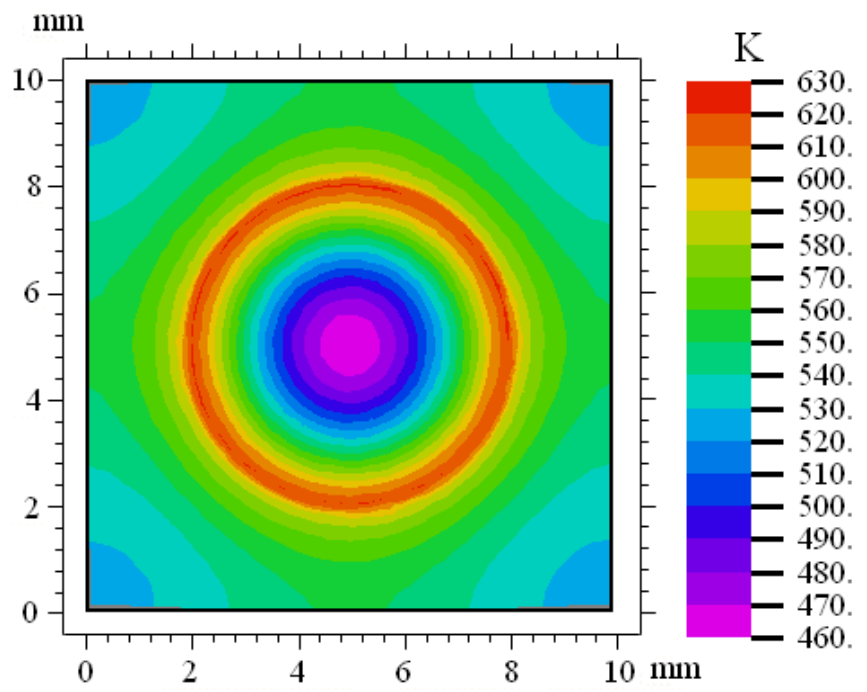

Figure 10: Calculated temperature field on silicon chip surface under laser ring illumination, with the silicon chip placed on a copper boss with 3 um air gap after 2 seconds illumination

\section{Localised heating with scanning focused laser beam}

An alternative way of realising localised heating is to use a scanning focused laser beam. For these experiments the same laser system as above was used. Instead of using the axicon-lens arrangement to generate a ring focus the laser beam is scanned across the sample with a scan head. The experimental setup is shown in figure 11. The diameter of the BCB ring is $6.5 \mathrm{~mm}$, the ring width is $0.3 \mathrm{~mm}$ and the thickness is 15 microns. The force applied during processing was $3.92 \mathrm{~N}$ as previously.

Experiments based on copper block cooling were carried out. Firstly, we used a high scanning speed of $1000 \mathrm{~mm} / \mathrm{s}$ and $200 \mathrm{~W}$ to provide localised heating, however we did not succeed as expected because of the temperature being not high enough to cure the BCB. When we decreased the scanning speed to $0.5 \mathrm{~mm} / \mathrm{s}$ at a power of 80 and $90 \mathrm{~W}$, successful bonding was achieved which was demonstrated by the neutral colour of the bonded BCB under a microscope. Tempilaq paint demonstrates that the temperature in the centre of the silicon was always higher than $422 \mathrm{~K}$ but less than $457 \mathrm{~K}$.

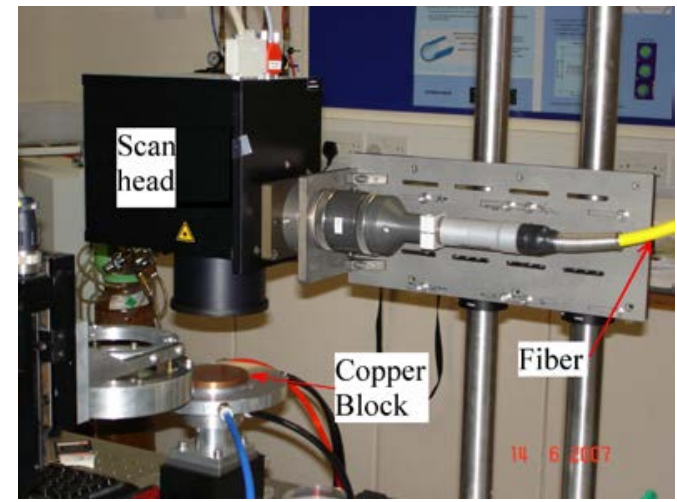

Figure 11: The experimental setup with scan head

Fine leak test results by through-hole testing method are listed in table 2 . The background signal is measured at around $2.5 \times 10^{-10} \mathrm{mbar} \mathrm{l} \mathrm{s}^{-1}$. 
Table 2 Fine leak test results of the bonded samples with scanned laser beam by using copper block cooling unit

\begin{tabular}{|c|c|c|c|c|}
\hline $\begin{array}{c}\text { Laser scan } \\
\text { speed }(\mathrm{mm} / \mathrm{s})\end{array}$ & $\begin{array}{c}\text { Laser Power } \\
(\mathrm{W})\end{array}$ & $\begin{array}{c}\text { Number of } \\
\text { passes }\end{array}$ & $\begin{array}{c}\text { Bonding } \\
\text { time }(\mathrm{s})\end{array}$ & $\begin{array}{c}\text { Leak rate } \\
\left(\mathrm{mbar} \mathrm{l} \mathrm{s}^{-1}\right)\end{array}$ \\
\hline 0.5 & 80 & 1 & 45.5 & $3.3 \times 10^{-10}$ \\
\hline 0.5 & 90 & 1 & 45.5 & $4.6 \times 10^{-10}$ \\
\hline
\end{tabular}

Table 2 shows that leak rates as low as $10^{-10} \mathrm{mbar} \mathrm{s} \mathrm{s}^{-1}$ were achieved which is close to the background noise of the leak test machine. However this technique would result in a long bonding time because the laser used cannot provide enough power to use the high speed scanning method. Therefore the copper block was substituted by a copper boss as this cooling method requires considerable lower laser powers. Experiments based on copper boss cooling by using high scanning speed of $1000 \mathrm{~mm} / \mathrm{s}$ were also carried out. Table 3 gives experimental results with different laser powers and bonding times. The background signal is measured at $<1.0 \times 10^{-11} \mathrm{mbar} \mathrm{l} \mathrm{s}^{-1}$ (Detection limit of He leak tester).

Table 3 Fine leak test results of the bonded samples with scanned laser beam by using copper boss cooling unit

\begin{tabular}{|c|c|c|c|}
\hline $\begin{array}{c}\text { Laser scan } \\
\text { speed (mm/s) }\end{array}$ & $\begin{array}{c}\text { Laser Power } \\
(\mathrm{W})\end{array}$ & $\begin{array}{c}\text { Bonding } \\
\text { time (s) }\end{array}$ & $\begin{array}{c}\text { Leak rate } \\
\left(\mathrm{mbar} \mathrm{l} \mathrm{s}^{-1}\right)\end{array}$ \\
\hline 1000 & 50 & 15 & $2.9 \times 10^{-10}$ \\
\hline 1000 & 60 & 15 & $4.3 \times 10^{-10}$ \\
\hline 1000 & 60 & 10 & $2.9 \times 10^{-10}$ \\
\hline 1000 & 70 & 5 & $6.9 \times 10^{-10}$ \\
\hline 1000 & 90 & 2 & $3.8 \times 10^{-10}$ \\
\hline 1000 & 140 & 1 & $3.9 \times 10^{-10}$ \\
\hline
\end{tabular}

Table 3 indicates that the leak rate is not significantly affected by the laser power. The bonding time can be as short as 1 second with a very low leak rate at a value of $10^{-10}$.

Tempilaq paint demonstrates that the temperature in the centre of the silicon was always higher than $477 \mathrm{~K}$ but less than $505 \mathrm{~K}$.

\section{Discussions and conclusions}

We have demonstrated localised laser heating to bond glass to silicon using an intermediate layer of BCB which is an enabling technology allowing for packaging of temperature sensitive devices. Two techniques for providing localised heating by a laser were tested experimentally. The first was to use an axicon together with a positive lens to generate a focused ring. With appropriate heat sinking, a suitable temperature could be reached for curing the BCB, whilst maintaining a relative lower temperature at the centre of the package; however an improved thermal contact will be necessary to keep this closer to ambient temperature. This axicon arrangement is however limited to a circular geometry; in future we will explore alternative optical arrangements to generate temperature fields with alternative shapes.

Our second technique was to use a scanning focused laser beam. Two kinds of heat sink were used in our experiments. One is to use a copper block as cooling sink. Experiments show that we can get excellent bonding with a very low scanning speed of $0.5 \mathrm{~mm} / \mathrm{s}$, whilst maintaining a low temperature at the centre of the silicon. However this significantly increases the bonding time (45.5s). Another is to use a copper boss as cooling sink. This technique could save a significant amount of laser energy and made it possible to use high scanning speed $(1000 \mathrm{~mm} / \mathrm{s})$ to realize localised heating. Experimental results show that we can realize excellent bonding with bonding times as short as 1s, whilst keeping the centre of the silicon at a relatively low temperature. So far single chip packaging has been demonstrated but the short bonding time makes this approach also feasible for wafer-level packaging. Future 
investigations are aimed at scaling the process up to wafer-level and alterations to the bonding setup to allow for vacuum packaging.

\section{References}

[1] M. X. Chen, L. L. Yuan, S. Liu, "Research on low-temperature anodic bonding using induction heating", Sens. and Actua. A-Phys., vol. 133, pp. 266-269, Jan. 2007.

[2] P. Yu, C. Pan, J. Xue, “The anodic bonding between K-4 glass and Si”, Materials Lett., vol. 59, pp. 2492-2495, Aug. 2005.

[3] S. D. Wolter, G. N. Yushin, F. Okuzumi, B. R. Stoner, J. T. Prater, Z. Sitar, "Direct fusion bonding of silicon to polycrystalline diamond”, Diamo. and Relat. Mater., vol. 11, pp. 482-486, Mar.-Jun. 2002.

[4] G. N. Yushin, S. D. Wolter, A. V. Kvit, R. Collazo, B.R. Stoner, J. T. Prater, Z. Sitar, "Study of fusion bonding of diamond to silicon for silicon-on-diamond technology”, Appl. Phys. Lett., vol. 81, pp. 3275-3277, Oct. 2002.

[5] K. I. Kim, J. M. Kim, J. M. Kim, G. C. Hwang, C. W. Baek and Y. K. Kim, "Packaging for RF MEMS devices using LTCC substrate and BCB adnesive layer”, J. Micromech. Microeng, vol. 16, pp. 150-156, Jan. 2006.

[6] I. Christiaens, G. Roelkens, K. D. Mesel, D. V. Thourhout, and R. Baets, "Thin-film devices fabricated with Benzocyclobutene adhesive wafer bonding”, J. Light. Techn., vol 23, pp. 517-523, Feb. 2005.

[7] Cyclotene 4000 series Resin Data, [online] Available: http://www.dow.com/cyclotene/solution/4000hot.htm

[8] F. Bardin, S. Kloss, C. Wang, A.J. Moore, A. Jourdain, I.D. Wolf, D.P. Hand, "Laser bonding of glass to silicon using polymer for Microsystems packaging”, J. Microelectromech. Syst., vol. 16, pp. 571-580, June 2007

[9] L. Lin, "MEMS post-packaging by localized heating and bonding", IEEE Trans. on Adva. Pack., vol. 23, pp. 608-616, Nov. 2000.

[10] L. Lin, Y. T. Cheng, and K. Najafi, "Formation of silicon-gold eutectic bond using localized heating method," Jpn. J. Appl. Phys. 2, Lett., vol. 37, pp. L1412-L1414, Nov. 1998.

[11] Y. T. Cheng, W. T. Hsu, K. Najafi, C. T. C. Nguyen, and L. Lin, "Vacuum packaging technology using localized aluminum/silicon-to-glass bonding,” J. Microelectromech. Syst., vol. 11, pp. 556-565, Oct. 2002.

[12] R. J. K. Wassink, Soldering in Electronics. Ayr, U.K.: Electrochemical Publications, 1984.

[13] H. Noh, K. Moon, A. Cannon, P. J. Hesketh, and C. P. Wong, "Wafer bonding using microwave heating of parylene for MEMS packaging,” in Proc. IEEE Int. Conf. Electron. Compon. and Technol., 2004, vol. 1, pp. 924-930.

[14]H. A. Yang, M. Wu, and W. Fang, "Localized induction heating solder bonding for wafer level MEMS packaging,” in Proc. IEEE Int. Conf. Micro Electro Mech. Syst., 2004, pp. 729-732. 